July 2018

\title{
Teaching the Monty Hall Dilemma to Explore Decision-Making, Probability, and Regret in Behavioral Science Classrooms
}

Kevin L. Bennett

Penn State University, Beaver, klb48@psu.edu

Follow this and additional works at: https://digitalcommons.georgiasouthern.edu/ij-sotl

\section{Recommended Citation}

Bennett, Kevin L. (2018) "Teaching the Monty Hall Dilemma to Explore Decision-Making, Probability, and Regret in Behavioral Science Classrooms," International Journal for the Scholarship of Teaching and Learning: Vol. 12: No. 2, Article 13.

Available at: https://doi.org/10.20429/ijsotl.2018.120213 


\title{
Teaching the Monty Hall Dilemma to Explore Decision-Making, Probability, and Regret in Behavioral Science Classrooms
}

\author{
Abstract \\ The Monty Hall Dilemma (MHD), made famous by the television game show Let's Make a Deal, can be an \\ effective teaching tool with wide ranging behavioral science applications. The format and history of the \\ problem are presented as well as experimental data and variations on the original design. Strategic game \\ playing choices are discussed from several perspectives including statistics, decision making, social and \\ personality psychology, and cognitive functioning. Because the classroom exercise is engaging and \\ counterintuitive, it challenges students to generate explanatory ideas that draw from multiple \\ perspectives. It exemplifies the type of detective work and creative thinking that is central to doing \\ research in the behavioral sciences, and it can be applied to fields as diverse as sociology, religious \\ studies, biology, and behavioral economics.

\section{Keywords} \\ Monty Hall, Decision-Making, Probability, Statistics, Committment, Regret, Teaching Psychology

\section{Creative Commons License} \\ c) (i) $\ominus$ \\ This work is licensed under a Creative Commons Attribution-Noncommercial-No Derivative Works 4.0 \\ License.

\section{Cover Page Footnote} \\ Address correspondence to Kevin Bennett, Penn State Beaver, Department of Psychology, Monaca, PA \\ 15061; via e-mail: klb48@psu.edu
}


IJ-SoTL, Vol. 12 [2018], No. 2, Art. 13

\title{
Teaching the Monty Hall Dilemma to Explore Decision-Making, Probability, and Regret in Behavioral Science Classrooms
}

\author{
Kevin L. Bennett \\ Penn State University, Beaver \\ (Received 4 October 2017;Accepted I3 December 2017)
}

\begin{abstract}
The Monty Hall Dilemma (MHD), made famous by the television game show Let's Make a Deal, can be an effective teaching tool with wide ranging behavioral science applications. The format and history of the problem are presented as well as experimental data and variations on the original design. Strategic game playing choices are discussed from several perspectives including statistics, decision making, social and personality psychology, and cognitive functioning. Because the classroom exercise is engaging and counterintuitive, it challenges students to generate explanatory ideas that draw from multiple perspectives. It exemplifies the type of detective work and creative thinking that is central to doing research in the behavioral sciences, and it can be applied to fields as diverse as sociology, religious studies, biology, and behavioral economics.
\end{abstract}

\section{INTRODUCTION}

The original version of Monty Hall's Let's Make a Deal was a successful television program for over 25 years because the rules were uncomplicated and the prizes were deceptively easy to win. The game show posed a frustratingly simple dilemma to contestants: stay with your initial guess or switch to another option. Aside from Hollywood embellishments, like offering cash to influence choices and encouraging audience members to dress in outrageous costumes, the format was relatively straight forward. In addition to addressing probability issues in statistics, the Monty Hall Dilemma (MHD) can be used to teach a number of issues in the behavioral science and beyond. I like to challenge students to tackle the problem from several perspectives including statistics, decision making, social and personality psychology, and cognitive functioning. One of the outcomes of teaching MHD is that students - guided by spirited class discussion - are often inspired to push the problem far beyond its original form. Examples of this include applications to behavioral economics, sociology, and religion.

\section{Benefit to the Scholarship of Teaching and Learning}

The Scholarship of Teaching and Learning (SoTL) will benefit from the ideas presented here in at least two important ways: (I) Following the work of Bass (1999), the application of MHD is accessible to others practicing teaching and learning. In this sense, it is consistent with the view that rather than private practice, teaching should be public and community oriented (Huber, 2009; Hutchings, 2007). (2) Central to the concept of SoTL is the idea that teaching is a window into student learning. As such, when content is pulled from different fields, philosophical orientation, methodologies, and interests, these works should share an intersection that that is focused on improved student learning. (Gilpin, 2007). The MHD game discussed here provides support for both of these key points.

\section{Playing the Monty Hall Game}

The game show is easy to reproduce in class and typically takes this format: Monty Hall, a thoroughly honest game show host, has placed a new car behind one of three doors. There is a goat behind each of the other doors. "First, you point toward a door," he says. "Then l'll open one of the other doors to reveal a goat.After l've shown you the goat, you make your final choice, and you win whatever is behind that door." You begin by pointing to a door, say door I. Monty, knowing full well what is behind all the doors, shows you that door 3 has a goat. What will your final choice be? Stick with door I? Or, Switch to door 2? (See Figure I). Of course, it is assumed that you desire the car, not one of the goats.

Figure I. The basic format of the Monty Hall Dilemma requires three doors and uses these instructions

Monty Hall, a thoroughly honest game-show host, has placed a new car behind one of three doors. There is a goat behind each of the other doors. "First, you point toward a door," he says. "Then l'll open one of the other doors to reveal a goat. After l've shown the goat, you make your final choice, and you win whatever is behind that door." You begin by pointing to door number I.

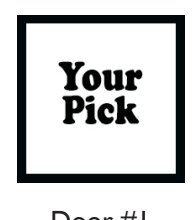

Door \#I

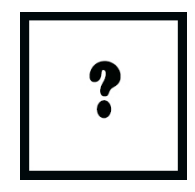

Door \#2

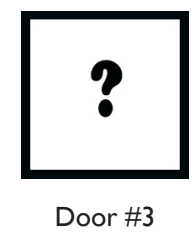

Monty then shows you that door 3 has a goat:

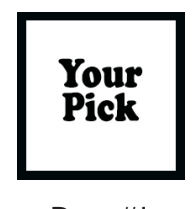

Door \#I

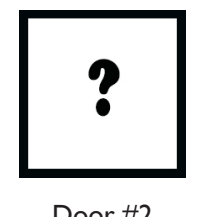

Door \#2

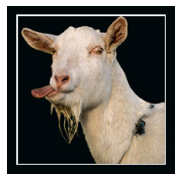

Door \#3

What would your final choice be?

Stick with door I

Switch to door 2

The correct strategy, if you want to win the car more often than not, is to always switch doors! Don't give this up right away let students wrestle with the decision. Here is how it works. The probability of winning under the stay-strategy is .33. Only when the initial choice is correct can a player win under this strategy. Many people think that a switch-strategy will not improve chances for winning, but it does. The initial pick is always random 
(door 1, 2, or 3), but the information the host reveals about one of the other doors is not random. The switch-strategy essentially minimizes the chances of losing because a loss will only occur when the initial choice is correct (33\% of the time this will be true). Thus, a switch-strategy will produce a win $67 \%$ of the time $(\mathrm{I}-.33=.67)$. Table $\mathrm{I}$ provides a list of all possible outcomes under both strategies and demonstrates that the switch-strategy doubles the probability of winning the prize. For a mathematical proof using probability notation see Selvin (1975).

Table I. All possible outcomes for stay and switch strategies in the Monty Hall Dilemma

\begin{tabular}{|c|c|c|c|c|}
\hline \multicolumn{5}{|c|}{ All possible outcomes for stay-strategy:: } \\
\hline $\begin{array}{c}\text { Correct Door } \\
\text { (unknown to } \\
\text { contestant) }\end{array}$ & $\begin{array}{c}\text { I }^{\text {st }} \\
\text { Choice }\end{array}$ & $\begin{array}{c}\text { Exposed } \\
\text { Door }\end{array}$ & $\begin{array}{c}\mathbf{2}^{\text {nd }} \\
\text { Choice }\end{array}$ & Result \\
\hline A & A & B or C & A & WIN \\
\hline A & B & C & B & lose \\
\hline A & C & B & C & lose \\
\hline B & A & C & A & lose \\
\hline B & B & A or C & B & WIN \\
\hline B & C & A & C & lose \\
\hline C & A & B & A & lose \\
\hline C & B & A & B & lose \\
\hline C & C & A or B & C & WIN \\
\hline & & & $3 / 9$ WINS $=33 \%$
\end{tabular}

All possible outcomes for switch-strategy::

\begin{tabular}{|c|c|c|c|c|}
\hline $\begin{array}{c}\text { Correct Door } \\
\text { (unknown to } \\
\text { contestant) }\end{array}$ & $\begin{array}{c}\text { I }^{\text {st }} \\
\text { Choice }\end{array}$ & $\begin{array}{c}\text { Exposed } \\
\text { Door }\end{array}$ & $\begin{array}{c}\mathbf{2}^{\text {nd }} \\
\text { Choice }\end{array}$ & Result \\
\hline A & B & C & A & WIN \\
\hline A & C & B & A & WIN \\
\hline A & A & B or C & C or B & lose \\
\hline B & A & C & B & WIN \\
\hline B & C & A & B & WIN \\
\hline B & B & A or C & C or A & lose \\
\hline C & A & B & C & WIN \\
\hline C & B & A & C & WIN \\
\hline C & C & B or A & A or B & lose \\
\hline
\end{tabular}

$6 / 9$ WINS $=67 \%$

Note: The correct strategy is to always switch . Using a stay-strategy, winning will occur only when the first choice is correct ( $33 \%$ win). Using a switch-strategy, losing will occur only when first choice is correct (33\% lose and $\mathrm{I}-33 \%=67 \%$ win). Because the game show host always knows the correct door, he or she will sometimes have a choice between exposing two doors (e.g., B or C).

Several options exist for demonstrating this in class. Most teachers don't have access to a fully operational television studio complete with doors, cars, and goats. I prefer three large cards with prizes drawn on the opposite sides. This reassures students that the game is not fixed. As the host, you need to be aware of what is behind all the doors before you turn one over, so be sure you set up the cards so that you are the only one with access to the back sides. A computer presentation would also work, but for this task it might be wise to let parsimony carry the day.
Besides, cynical audience members might question the veracity of your performance if they detect even the slightest whiff of technological legerdemain. For added reality, one could raise the stakes by replacing the car prize with extra credit points and allowing the students play whatever strategy they wish. However, student anxiety being what it is, the most comfortable and controlled approach might be to play with pretend prizes. Assign half of the class to play the stay-strategy and half to play the switch-strategy.Across trials, those who play the switch-strategy will have more success.

The MHD poses at least two teaching challenges. The first is to get students to understand why the correct strategy is to switch. This is part of the intrigue of the problem, but many students will express disbelief over this solution. Don't be surprised if you are ambushed with incredulous statements along the lines of "how can that be?" or "it just doesn't make sense." An effective way to convince doubters is to follow the demonstration with an examination of all the possible outcomes (Table I). I've found that emphasizing the probability of winning under the stay-strategy and emphasizing the probability of losing under the switch strategy is most helpful. In addition, encourage students to try the game on friends or, as I did, by conducting a solo empirical investigation comparing success rates using three cards and a commitment to act honestly as host and contestant simultaneously. A second challenge involves focusing classroom discussion on the relevant psychological explanations that account for performance on this task (performance is poor, as we shall see below). Students will undoubtedly have opinions on this matter - some will be intuitive, others will be grounded in theory. The following sections address both of these classroom challenges.

\section{History of the Problem}

Increased attention over the past decade has moved the MHD from a peripheral issue in mathematics to the prevailing current of modern psychology. For example, Kelley (2004) illustrates this hot topic in the context of cognitive shortcuts, but the MHD is hardly new. Versions of this problem have been traced back to $17^{\text {th }}$ century philosophy texts, but the first contemporary form appeared in a 1959 issue of Scientific American in the "Mathematical Games" section. The structure of the problem was the same, but the story involved a governor's pardon being given to one of three prisoners (Gardner, 1959a, 1959b). The dilemma became well known between 1963 and 1990 on Monty Hall's television show, but the controversy over the correct solution started after Marilyn vos Savant presented this problem to her readers and said that the best strategy was to switch (vos Savant, 1990a, 1990b, 199 la, 199b). vos Savant, the popular columnist and Guinness Book record holder of highest I.Q., stood by her answer despite the thousands of letters insisting she was wrong. Of all the letters she received, $92 \%$ said she was wrong. Of the letters from universities, $65 \%$ were against her answer. The debate that followed was acrimonious, but in the end she proved to be correct. For an enlightening discussion of false solutions see Morgan, Chaganty, Dahiya, and Doviak (1991a, I99 Ib, I99/c).

\section{Experimental Data and Variations of the Game}

The problem has generated debate among statisticians, mathematicians, and the popular press (Tierney, 1991), paving the way for psychologists to inquire about actual performance. In gen- 
eral, research suggests that people are terrible at getting this problem correct, especially the first time around. Granberg and Brown (1995) found that only I3\% of subjects opted to switch on the first trial (the correct answer), and Granberg and Dorr (1998) found $8 \%$ were willing to switch. Similar rates are found cross-culturally: Brazil 13\%, China 21\%, Sweden 17\%, and U.S. 16\% (Granberg, 1999). Students will be pleased to learn that they are not the only ones performing below optimality.

Even when participants play the game over many trials they have a difficult time learning inductively to switch. In one study, switching was very low at the beginning (about 10\%) and reached a plateau between $50-60 \%$ near the end of 50 trials (Granberg \& Dorr, 1998). One might expect that after many trials individuals would learn the best strategy and switching would hover closer to $100 \%$. This is not the case.

In the symmetrical counterpart to the game, called the Russian Roulette Dilemma (Granberg \& Brown, 1995), subjects are told that there are two cars and only one goat behind the three doors. A door is picked (say door I), and then a car is exposed behind one of the two remaining doors (say door 3 ). What would your final choice be? Stick or switch? In this scenario, it is correct to stay with your first pick because the probability of picking a door with a car on the initial guess is .67 . This probability does not change when the host deliberately shows that one of the other doors has a car behind it. Results show that $31 \%$ of people switch (the wrong strategy) and 69\% of people stay (the correct strategy). Although almost $70 \%$ of people use the correct strategy here, a larger number of people than in the original version feel that switching is the best approach. For the most part, when people should stay in order to maximize benefits, they do so. When they should switch, however, there is an overwhelming tendency to stay.

In another version of the game, Granberg and Dorr (1998) measured the effect of switch vs. stay strategies after manipulating the total number of doors used in the experiment and the number of incorrect doors shown. The total number of doors varied between three, five, and seven. For each of those conditions, either one incorrect door was opened or N-2 incorrect doors are opened (all but one incorrect door). Showing all but one incorrect door should make the solution less ambiguous as the total number of doors increases. For example, in the case of $\mathrm{N}=7$ doors, let's say the player picks door I. The host then exposes 5 incorrect doors leaving only the initial pick and one other door. Should you switch to the other door or stay with your initial pick? Statistically, you should switch doors because of the advantage you get with each door that is opened. Each incorrect door that is exposed provides additional information. Results for a one-trial experiment do not show this trend. In fact, $25 \%$ of the people switch when there are 7 total doors and only I incorrect door is shown, but only II\% switch when there are 7 total doors and 5 incorrect doors are shown.

Across 50 trials, the percentage switching on the final 10 trials increases for all the conditions, but seems to top out around $50-60 \%$ for the conditions where one incorrect door is shown. For the conditions in which $\mathrm{N}-2$ incorrect doors are shown, the percent switching is much higher. With 5 total doors and 3 incorrect exposed, the percent switching is $76 \%$, and with 7 doors and 5 incorrect exposed the percentage is $87 \%$. One might expect this percentage to increase as conditions with more doors are included. When enough information is provided it seems that people can adopt the correct strategy, to some extent, if they practice over many trials.

\section{Psychology Applications}

What use does the field of psychology have for a game show that first aired over 50 years ago? In general, research on the MHD shows that people have a propensity to stay with an initial hunch when they should switch. With few exceptions, it is not easy for people to learn to switch when they ought to. This consistent finding can be used as a centerpiece for exploring a number of topics.

Commitment and Regret. Some researchers have argued that people are using a cognitive heuristic of mental simulation when they play this game. "How will I feel if I switch and lose?" they ask themselves, and "How will I feel if I stay and lose?" Gilovich, Medvec, and Chen (1995) used the MHD to demonstrate that people who switch and then lose experience more regret and psychological pain than those who stay and lose. Similarly, some students experience this when they change their answers on a multiple choice test only to learn afterwards that their initial hunch was correct.

Perhaps there is something special about making a commitment? Is there an intimate relationship between commitment, regret, and pain? Researchers have observed that there is an inconsistency between "experimental regret" and what people say about "everyday regret." It is common to hear people say, when reflecting upon the past, that they regret the things that they haven't done in life (e.g., talked to an attractive person, gone skydiving, etc.). Laboratory data suggest just the opposite - that people regret acts of commission that have negative outcomes more than acts of omission that have negative outcomes (Gilovich, Medvec, \& Chen, 1995). Most of us would feel distressed over losing out on a lottery jackpot after we had changed our numbers from the winning combination to some other pick. It would probably be better just to lose with our first pick.

Decision Making Bias. What is the underlying cognitive psychology being played out with the MHD? The initial selection in the game may result in a cognitive bias that inhibits switching from the first choice. Granberg \& Dorr (1998) found that switching increases to $38 \%$ when another person makes the final decision to switch or stay. That is, one person would make the initial selection and a second person, who is not committed one way or the other to the first person's selection, makes the final decision. This significant increase in switching provides some support for the idea that the propensity to stay comes from a false illusion of control. When this illusion is lessened or removed, the likelihood of a switch increases. However, having the initial guess made by another person did not offer an advantage in the long run. In trials 2 I-50, the one-person players were switching at the same rate as the two-person players (about $50 \%$ of the time).

Cognitive Illusion. The MHD may be difficult to solve because it is so uniquely contrived and humans are not designed for objective information processing in this domain. I've heard statisticians say that the human brain is simply not wired for dealing with many issues of statistical probability. However, the Monty Hall game is not complex and does not require differential calculus equations or sophisticated mathematics to play. One reason the problem is so appealing is because of its simplicity. It is a charming two-stage conditional probability problem where one makes a tentative decision, gains information, and makes a final 
commitment. I disagree with those who are tempted to treat the problem as an interesting but artificial puzzle that does not warrant the attention of psychology. The MHD deserves consideration because it is an example of something humans don't do very well. One way to merge the MHD with the teaching of human cognition is to use this game as an example of something at which humans are not very good. As teachers of psychology, we should be curious about behaviors that reduce success as well as behaviors that lead to successful outcomes.

\section{Real World Analogs and Structural Variations}

I like to ask students to think of real life examples of the MHD. Are there any? To answer this one must find situations outside the lab that meet these criteria: (I) choices must be made that involve no prior knowledge about the different options; (2) there exists the equivalent of a knowledgeable host who knows the "winning" option as well as your choice; (3) the host is capable of and willing to reveal an incorrect answer. I am unaware of any equivalent context shift for the MHD, but the point of thinking about real world analogs is to entertain the idea that people are learning how to solve the problem in life tasks that could be applied to this problem. The goal is not necessarily to get people to perform better on the Monty Hall show, but to see if shifting contexts will result in better performance - thus shedding light on some aspect of human information processing.

This approach is similar to some fascinating work on the evolution of cheater detection that involved looking at how individuals navigate through tasks that are constructed differently (Cosmides, 1989). This research has shown that people perform poorly on the Wason selection task when it is presented in its traditional form as a logic puzzle with numbers and letters (e.g., "if $P$ then $Q$ " or "if A then 4"). However, when the problem is reformulated as an ecologically valid cheater detection task (e.g., "in order to drink beer one must be over 21 ") people perform much better. The argument is that the human brain is quite capable of reasoning through the problem when it is placed in a more familiar context. Would performance on the MHD improve if one could find a similar context shift? Over the years l've heard a slew of examples of real world analogs from students. These have been thought provoking but, for various reasons, all have failed to match the conditions for an ecologically valid MHD. Here are a few examples.

Imagine betting on a horse race with only three entries and you put your money on horse I. Midway through the race, horse 3 falls over and is no longer a contender. Assuming the track would allow you to switch your bet during the race, should you now put your money on horse 2? The correct answer is "no" because this scenario lacks someone who knows the correct answer. Seymann (199I) refers to the complication in this example as a "problem definition." The information provided by horse 3 is not dependent on your initial pick, thus, it is irrelevant. This may partly explain why people perform poorly on the MHD - in real life there is rarely a situation where an all-knowing host is participating in our decisions.

An example from a typical grocery store looks like a good candidate for a Monty Hall situation. We've all been in the position to choose between several (perhaps even 3 ) checkout lines at the grocery store. Once committed to a line there is often a temptation to switch to a faster moving line. This superficial- ly represents the dilemma, but is not true in structure. As with the horse racing example, there is no knowledgeable host. In addition, there is a great deal of available information to take into account such as the speed of each cashier, the number of customers in each line, and the quantity of items in each shopper's basket. The MHD does not allow for this much additional information.

Students interested in the psychology of religion and the perception of higher powers might be inclined to place God, or some equivalent entity, in the position of the game show host. This scenario comes fairly close to satisfying the criteria because, unlike the previous examples, it includes a knowledgeable host. One could assume that people face difficult choices in life (the three doors), some superior being knows the correct path in life (the honest game show host), and he, she, or it is willing to reveal an incorrect option (behind one of the doors is a goat). This analogy works up to a point and students will have fun dissecting it. "When God closes a door he opens a window," said one student referring to the popular expression about the mysterious ways of religion. Close, but no cigar. Other students were quick to point out that this message conveys meaning about the commitment to a wrong choice - not information about some option we did not take. If Monty Hall were to adhere to this aphorism he would just show people that their initial choice was wrong! Sorry, you picked a goat. Now try another door.

Returning to more practical teaching applications, the dilemma can be used to introduce specific techniques that social, personality, and developmental psychologists might use. Researchers have yet to explore basic correlations between strategy choices and aspects of personality. This approach would be useful in deriving broad personality profiles of successful and unsuccessful players. Or, students could generate more specific predictions. Using a personality inventory, one might be able to differentiate the people who are unsuccessful at optimally solving this task from the small number of individuals who are successful on the initial trial. (e.g., those who are able to negotiate the dilemma correctly tend to be higher on "neuroticism" or "risk taking"). A developmental psychology approach might include a discussion of the emergence of traits along a developmental timeline. If the MHD is related to emotions such as regret, guilt, or pain it could be fruitful to examine children's performance on this task before and after those emotions take shape. Perhaps certain children will demonstrate remarkable levels of switching, even outperforming adults? This lesson could be coupled with a discussion both children's and adults' tendencies to change strategies as a result of observational learning. Who is more likely to change playing patterns after watching someone repeatedly win or lose using the two strategies? The applications are wide ranging and the game provides a starting point for a myriad of investigative questions that call for creative, analytical, and practical thinking.

\section{REFLECTIONS AND FUTURE DIRECTIONS}

MHD is an effective and engaging learning tool that prompts students to apply psychology in novel and productive ways to a 50-year-old game show. This learning tool fits in nicely with the values promoted by the growing SoTL movement. Building on past assessment traditions in higher education, the SoTL approach is designed to develop pedagogical expertise through reflection, analysis, and public promotion inquiry findings. Future 
research in this area should attempt to measure empirically the increase in learning using MHD. For example, is it the case that students in statistics classes who work with MHD also understand probability theory in general? The experimental design for such an inquiry would likely involve assessing math and probability skills using a between-subjects design. One group of students would get the MHD treatment, the other group would get traditional teaching approaches to probability concepts. All students would then be measured for knowledge gains in this area.

Regardless of how much time and attention you give to the issue of explaining the MHD, it is well worth your while to introduce the problem in class. In my statistics courses I like to present the problem on the first day of class with a cliff-hanger ending that promises the correct solution when we get to the course material covering probability (Bennett, 2004). In other courses, the problem is discussed at length in one class period and concludes with the request that students pursue the topic further. Or, use it as an end of the semester laboratory that urges students to tap into their psychology breadth for answers and discussion.

\section{REFERENCES}

Bass, R. (1999). The scholarship of teaching:What's the problem? Inventio: Creative Thinking about Learning and Teaching, I (I).

Bennett, K. L. (2004). How to start teaching a tough course: Dry organization versus excitement on the first day of class. College Teaching, 52(3), 106.

Cosmides, L. (1989). The logic of social exchange: Has natural selection shaped how humans reason? Studies with the Wason selection task. Cognition, 3 I, I87-276.

Gardner, M. (1959a). Problems involving questions of probability and ambiguity. Scientific American, 20 I, I74- 182.

Gardner, M. (1959b). How three modern mathematicians disproved a celebrated conjecture of Leonhard Euler. Scientific American, 20I, I8I- 188.

Gilovich, T., Medvec, V. H., \& Chen, S. (1995). Commission, omission, and dissonance reduction: Coping with regret in the "Monty Hall" problem. Personality and Social Psychology Bulletin, 21 , $182-190$.

Gilpin, L. S. (2007). Unearthing the scholarship of teaching and learning in self and practice. International Journal for the Scholarship of Teaching and Learning I(2), article 9.

Granberg, D. (1999). Cross-cultural comparison of responses to the Monty Hall dilemma. Social Behavior and Personality, 27, $431-438$.

Granberg, D., \& Brown,T.A. (1995). The Monty Hall dilemma. Personality and Social Psychology Bulletin, 2 I, 7 I I-723.

Granberg, D., \& Dorr, N. (1998). Further exploration of twostage decision making in the Monty Hall dilemma. American Journal of Psychology, I I I, 56 I-579.

Huber, M.T. (2009). Teaching travels: Reflections on the social life of classroom inquiry and innovation. International Journal for the Scholarship of Teaching and Learning 3(3), article 2.

Hutchings, P. (2007). Theory: The elephant in the scholarship of teaching and learning room. International Journal for the Scholarship of Teaching and Learning I(I), article 2.

Kelley, M.R. (2004). Demonstrating the Monty Hall dilemma. Teaching of Psychology, 3 I (3), I93-I 95.

Morgan, J. P., Chaganty, N. R., Dahiya, R. C., \& Doviak, M. J. (199la). Let's make a deal:The player's dilemma. The American Statis- tician, 45, 284-287.

Morgan, J. P., Chaganty, N. R., Dahiya, R. C., \& Doviak, M. J. ( 99 |b). Rejoinder. The American Statistician, 45, 289.

Morgan, J. P., Chaganty, N. R., Dahiya, R. C., \& Doviak, M. J. (I 99 Ic). Rejoinder to vos Savant. The American Statistician, 45, 347348.

Selvin, S. (1975). On the Monty Hall problem. The American Statistician, 29, 134.

Seymann, R. G. (199I). Comment. The American Statistician, 45, 287-288.

Tierney, J. ( I99I, July 21). Behind Monty Hall's doors: Puzzle, debate and answer? New York Times, Pp. I, 20.

vos Savant, M. (1990a, September 9). Ask Marilyn. Parade, Pp. 22. vos Savant, M. (1990b, December 2 ). Ask Marilyn. Parade, pp. 28. vos Savant, M. (199 Ia, February 17). Ask Marilyn. Parade, pp. 12.

vos Savant, M. (199/b). Letters to the editor. The American Statistician, 45, 347. 